\title{
APUNTES SOBRE LAS REFLEXIONES TEÓRICAS DE ULRICH BECK
}

\section{Ruslan Posadas Velázquez ${ }^{1}$}

\author{
Vivimos, pensamos y actuamos \\ con conceptos anticuados que, \\ no obstante, siguen gobernando \\ nuestro pensamiento \\ ynuestra acción.
}

Ulrich Beck

\section{Resumen}

En este artículo se hace un recuento general de los principales temas abordados por Ulrich Beck a lo largo de su obra, destacando como su noción sobre la Sociedad del Riesgo Mundial es el elemento articulador de los temas colaterales desarrollados en sus reflexiones teóricas.

Palabras Clave: Modemización Reffexiva, Sociedad del Riesgo Mundial, Subpolítica, Nacionalismo Metodológico, Categorías Zombis, Globalización,Individualización,FlexibilidadLaboralyCosmopolitismo

Parafraseando el comienzo de uno de los últimos artículos que Ulrich Beck escribió, en el que habla sobre los aportes a la sociología por parte de Zygmunt Bauman², podemos señalar que Beck no era un hombre común y corriente. Ulrich Beck no era un sociólogo común y corriente. Beck fue un tipo que tuvo la inteligencia de comprender un mundo en constante transformación y por eso su obra estuvo marcada por los entretelones de la configuración del llamado Nuevo Orden Mundial derivado de la Posguerra Fría.

En las siguientes líneas trataré de presentar de manera sintética algunas de las categorías más socorridas en la obra teórica de Beck, destacando los aspectos que las convierten por si mismas en reflexiones originales y generadoras de un intenso debate académico posterior.

\footnotetext{
${ }^{1}$ Doctor en Ciencias Políticas y Sociales por la UNAM. Profesor Investigador de la Academia de Ciencia Política y Administración Urbana de la Universidad Autónoma de la Ciudad de México (UACM) y Profesor de Asignatura en el Centro de Estudios en Administración Pública de la Facultad de Ciencias Políticas y Sociales de la UNAM. E-mail: ruslan.posadas@uacm.edu.mx ${ }^{2}$ Ulrich Beck, "Un voto a favor del regreso de la historia social". Disponible en URL: http://ssociologos.com/2015/02/03/elultimo-ensayo-de-ulrich-beck-elogiando-bauman-un-voto-favor-del-regreso-de-la-historia-social/
} 


\section{MODERNIZACIÓN REFLEXIVA}

Pudiera señalarse que en el mundo académico la discusión formal iniciada por Ulrich Beck para intentar acercarse al debate sobre las grandes transformaciones que estaba experimentando el mundo occidental a partir de la década de los 80 del siglo XX, data de un texto, publicado en 1994, que llevó por título Modernización Reflexiva. Política, Tradición y Estética en el orden social moderno, obra en la que Beck comparte créditos y debate vis à vis con Anthony Giddens y Scott Lash sobre los pormenores y dilemas que desentraña el falso debate modernidad versus posmodernidad, haciendo referencia a categorías como la destradicionalización, el riesgo, la crisis ambiental y la reinvención de la política.

Lo que comúnmente es visto, por el análisis formal, como un debate de familia debe ser analizado con más cuidado, ya que Beck marca distinciones teóricas y conceptuales importantes con Giddens y Lash, que lo llevan incluso a ser el centro de referencia del citado texto, pues muchos de los argumentos esgrimidos por ambos, se dan en función de respuestas a las tesis originales de Beck. Al final de ese libro existe incluso una sección de réplicas donde se hace más evidente la discrepancia entre Giddens y Lash con Beck.

El epicentro del debate estriba en que queda de manifiesto la noción propuesta por Beck de analizar los procesos sociopolíticos y socioeconómicos bajo el manto de la categoría Modernización Reflexiva, misma que trata de ser una respuesta al taciturno concepto de Posmodernidad que empezaba a cobrar fama en las reflexiones teóricas de los felices noventas.

La modernización reflexiva no se conceptualiza, de acuerdo con Beck, antes bien se presenta como "posibilidad de una (auto) destrucción creativa de toda época: la de la sociedad industrial. El sujeto de esta destrucción creativa no es la revolución, ni la crisis, sino la victoria de la modernización occidental”3.

Según Beck, el dinamismo de la sociedad industrial socava su propio fundamento y abre vías a una modernidad distinta, una modernidad que significa la desvinculación y luego revinculación de las formas sociales industriales por otro tipo de modernidad flexible y transformadora de estructuras. De ahí que una faceta de tal obsolescencia sea la aparición de sociedades de riesgo, porque las instituciones modélicas tienen cada vez menos control para evitar los riesgos para las que fueron creadas.

En ese tenor, para Beck si en algo es útil la reflexión sobre la nueva modernidad, no es necesariamente para contrapuntearla con quienes le han dado santa sepultura y corean al unísono la idea de la posmodernidad, sino, antes bien, para tomarla como punto de partida en el esbozo analítico de anatemas -los riesgos- que no habían sido vislumbrados por los creadores de la Gran Transformación ilustrada y de la posguerra.

\footnotetext{
${ }^{3}$ Beck, Ulrich; Giddens, Anthony; Lash, Scott, Modernización reflexiva. Política, tradición y estética en el orden social moderno, Madrid, Alianza Editorial, 1997, p.14.
} 
De ahí que la modernización reflexiva sirva de fundamento y punto de referencia para explicar no el mundo que se ha desdibujado, sino como un elemento para comenzar a entender el mundo trashumante que se modela literalmente día con día. Por esa razón, esta categoría es imperfecta y no busca respuestas ni soluciones, únicamente entendimientos y, en el mejor de los casos, puntos de referencia con su antecesora: la modernidad.

Realmente Ulrich Beck no apuesta por crear un nuevo marco normativo para este mundo en constante transformación, sino advertir sobre la necesidad de crear referentes de pensamiento abocados a explicar lo que está sucediendo y no lo que ya no sucede. Esto que parece un formalismo lógico es de lo que según Beck adolecen las ciencias sociales contemporáneas, mismas que continúan subsumiéndose en categorías de antaño que por sí mismas se vuelven obsoletas $-\mathrm{y}$ ridículas- al intentar comprender la nueva realidad que trajo la meta industrialización de la sociedad.

La modernización reflexiva viene a convertirse en ese espacio de debate necesario para la generación de ideas y propuestas que buscan dar rutas alternativas al orden que pretendidamente está establecido y, a su vez, tendría como propósito evitar el anquilosamiento de la explicación social, revitalizando para ello los elementos conceptuales y categoriales que la componen.

\section{SOCIEDAD DEL RIESGO MUNDIAL}

Múltiples fueron los campos sociales que enmarcaron las reflexiones teóricas de Ulrich Beck, sin embargo el brazo articulador de sus disertaciones fue su concepción sobre la que él llamó la Sociedad del Riesgo Mundial, categoría con la cual Beck intentó describir la democratización de las desgracias globales sin distinción de clase o estatus social, a contrapelo de las antiguas doctrinas políticas que ponían énfasis en la benevolencia social que otorgaba la pertenencia a las clases sociales favorecidas ${ }^{4}$.

De acuerdo con Beck, ese viejo paradigma, cuya égida se encuentra en el marxismo pero también en sus críticos, dejó de representar una veta de análisis a partir de la catástrofe nuclear de Chernóbil en $1986^{5}$ y de los problemas derivados del Cambio Climático ${ }^{6}$, pero también con las recurrentes crisis financieras globales desde

\footnotetext{
${ }^{4}$ Existen en castellano al menos 3 ediciones sobre el tema. Aunque todas ellas versan sobre ese planteamiento general, Beck ade cúa su planteamiento con los problemas de coyuntura en los periodos en que aparecen las sucesivas ediciones corregidas y aumentadas. Este es el orden cronológico de los textos: La sociedad del riesgo. Hacia una nueva modernidad, Barcelona, Paidós, 1998; La sociedad del riesgo. Amor, violencia, guerra, Madrid, Siglo XXI de España Editores, 2006; y La sociedad del riesgo mundial. En busca de la seguridad perdida, Barcelona, Paidós, 2008.

${ }^{5}$ La catástrofe en el reactor nuclear Vladimir Ilich Lenin, localizado a 18 kilómetros de la ciudad de Chernóbil (hoy Ucrania), sucedido el sábado 26 de abril de 1986 y que liberó materiales radiactivos y tóxicos al cielo de Europa estimados en 500 veces más que la bomba atómica lanzada en Hiroshima en 1945, marcó para Beck el recomienzo de la historia pero ahora en su fase del riesgo global.

${ }^{6}$ La Convención Marco de las Naciones Unidas sobre el Cambio Climático, en su Artículo 1, párrafo 2, establece que: "Por Cambio Climático se entiende un cambio de clima atribuido directa o indirectamente a la actividad humana que altera la composición de la atmósfera mundial y que se suma a la variabilidad natural del clima observada durante periodos comparables" vol.08, n.03, Rio de Janeiro, 2015.pp. 1760-1780 1762
} 
1990 hasta nuestros días, así como por la pulverización del poder del Estado para mediar los conflictos a través de la política social y de empleo, aunado al creciente individualismo institucionalizado.

Todos estos fenómenos representan para Beck las piezas del rompecabezas -literalmente hablandomundial que ponen de manifiesto la homogeneización de la sociedad a partir de los Males Públicos Globales y que, en ese sentido, demandan respuestas de la misma tesitura. A contracorriente de la mullida fórmula que reza "a problemas globales, soluciones locales", Beck optó por la respuesta más lógica, pero también más difícil de comprender y emprender: "A problemas globales, soluciones globales".

Por esa razón, el sociólogo alemán siempre pensó que para hacer frente a la Sociedad de Riesgo se demandaba el concurso de todos los actores políticos y sociales mundiales que pudieran entrelazar elementos de cooperación para hacer frente al alud de problemas anatemizados. Por esa razón, las respuestas en el nivel macro estaban en la configuración de un Estado Transnacional (cuyo modelo ideal para Beck era la Unión Europea ${ }^{7}$ ) que hiciera frente al poder fáctico de las empresas mundiales y de los organismos financieros globales. $\mathrm{O}$ bien en la consagración de una Sociedad Civil Mundial, cuyo marco de acción tendría que ser convergente con el Estado Transnacional, sobre todo en temas como la defensa del empleo y las políticas de bienestar.

En un nivel micro, materializable en el corto y mediano plazos, Beck proponía la creación de Partidos Políticos Mundiales, partidos que compartieran un mismo programa político para frenar los sinsabores del riesgo mundial y que compitieran electoralmente en distintos países de una región, a efecto de que una vez el poder pudieran tejer una red de intereses comunes que les permitiera fijar una agenda pública más allá de los intereses del mercado?.

A manera de sumario, Beck destaca que como proceso nuevo, la idea de la sociedad de riesgo nos acercó a una transformación de época en al menos tres direcciones:

1. La inviable relación de la sociedad industrial moderna con los recursos de la naturaleza y la cultura. Se consume mucho más de lo que se necesita y solo es a capricho del hiperconsumismo y de una noción

\footnotetext{
${ }^{7}$ Esta posición quedó expresada detalladamente, aunque de manera crítica, en el texto que Ulrich Beck escribió en coautoría con Edgar Grande intitulado La Europa Cosmopolita. Sociedad y Política en la Segunda Modernidad, Barcelona, Paidós, 2006. En ese texto, los autores afirman en tono desconsolado, y realista a la vez, que, en el fondo, la Europa Cosmopolita, es solo una utopía por los múltiples problemas de integración cultural y reconocimiento de los otros.

${ }^{8}$ Beck pensaba que las mínimas experiencias del mundo obrero europeo pudieran ser un buen indicador para hacer realidad esta postura. ¿Por qué a un obrero que trabaja para una empresa transnacional le debe importar la condición laboral de sus colegas en otro país? El autor creía que la nueva conciencia de clase debería pasar justamente por estas interrogantes, pues en la medida que se defendieran intereses de clase, o de otra tesitura, de manera transnacional, era justo ahí donde se podrían encontrar respuestas efectivas a problemas comunes y crear con ello una comunidad civil mundial.

${ }^{9}$ Aunque con matices, se puede decir que la serie de gobiernos identificados con las políticas de izquierda, que emergieron en Centroamérica y Sudamérica durante la primera década de este siglo, vienen a representar el ideal beckiano sobre la necesidad de transnacionalizar los procesos democráticos, ya que dichos gobiernos (Venezuela, Bolivia, Ecuador, Paraguay, Uruguay, Argentina, Brasil, Chile, Nicaragua y Honduras) formaron, en esos años, un frente relativamente exitoso contra las políticas del Consenso de Washington y reivindicaron el papel de esos Estados en la confección de la agenda pública latinoamericana.
} vol.08, n. 03, Rio de Janeiro, 2015.pp. 1760-1780 
delirante de progreso, hecho que conlleva a daños medioambientales y a su colapso en fenómenos como el calentamiento global.

2. La ambivalente relación de la sociedad con las amenazas que socavan los fundamentos de las ideas de seguridad. Ante la pasividad, negligencia o ineficacia de las instituciones estatales que fueron creadas para afrontar los problemas perentorios de las sociedades (como rezaba el canon del Estado de Bienestar), éstas se ven orilladas a buscar respuestas en otros espacios (organización colectiva emergente) o bien, como apunta el autor, a buscar soluciones biográficas a problemas creados globalmente, lo cual a la postre facilitó la conformación del individualismo institucionalizado.

3. Las fuentes de significado colectivo y la identidad sufrieron un agotamiento, quiebra y desencantamiento. La idea de la pertenencia a un Estado Nación al que se le debía jurar amor eterno, sencillamente se agotó y devino en múltiples expresiones identitarias y colectivas, lo mismo provocadas por los intensos flujos migratorios, que por la conformación de nuevos guettos en espacios nacionales, regionales o transnacionales.

Del primer elemento, Beck destaca la imperiosa necesidad de que transnacionalmente nos hagamos cargo de los daños medioambientales, pues tarde que temprano seremos alcanzados por ellos, sin distinción de posición social o preferencia ideológica. Sobre las dos últimas, Beck las concatena con la idea de la Individualización de la sociedad, pues "significa la desintegración de las certezas de la sociedad industrial y de la compulsión de encontrar y buscar nuevas certezas para uno mismo y para quienes carecen de ellas. Pero también significa nuevas interdependencias, incluso interdependencias globales. La individualización y la globalización son, de hecho, dos caras del mismo proceso de modernización reflexiva." ${ }^{10}$

Por esa razón es que la sociedad del riesgo es, de hecho, el eje articulador de toda la obra de Ulrich Beck. La referencia a ella siempre estará presente en sus disertaciones posteriores. Por ello, una mala lectura puede hacer de Beck un autor monotemático, en cambio una lectura que articule esta categoría con las que devienen de ella (la individualización, el trabajo flexible, la globalización) será más atinada para comprender la compleja estructura que diseña el pensador alemán a lo largo de su trayectoria académica.

\section{SUBPOLÍTICA}

Para Beck si en algo tangible se expresa la sociedad del riesgo es en el colapso de toda forma de control estatal sobre la sociedad. Al no crear y/o generar referentes para hacer fructífera su relación con la sociedad, el Estado sufre un proceso de descentramiento que lo conduce inevitablemente a dejar de ser el actor nodal que dirime los conflictos y propicia los consensos sociales. El extravío de rumbo estatal se expresa entonces en la

${ }^{10}$ Beck, Ulrich, et. al., p. 29. 
irrupción de otra forma de hacer política; en una superación de las prácticas políticas tradicionales y con ello de los actores que las llevaban a cabo. La emergencia de la sociedad demandante y contestataria es la simiente de la subpolítica.

Al existir un retorno de los individuos a la creación de espacios de discusión emerge también una ciudadanía activa que modela nuevas sociedades. La subpolítica significa entonces configurar la sociedad desde abajo; incorporando para ello a grupos históricamente suspicaces de la organización social. En ese contexto, pierde importancia el enfoque basado en el monopolio del poder central, pues de acuerdo con Beck: "La inmovilidad de los aparatos gubernamentales y sus agentes subsidiarios es perfectamente conjugable con la movilidad de los agentes en todos los niveles posibles de la sociedad, es decir, la extensión de la política puede acompañar la activación de la subpolítica"11.

Por esa razón, para Beck la modernización reflexiva se expresa también en la reinvención de lo político misma que "significa una política creativa y autocreativa que no cultive ni renueve las antiguas hostilidades, ni derive de ellas sus instrumentos de poder y los intensifique; en lugar de ello, se trata de una política que diseñe y forje nuevos contenidos, nuevas formas y nuevas alianzas. ( ... ) estructuras dentro y fuera del sistema político.” ${ }^{2}$. Si se ve de ese modo, ello implicaría por ejemplo una alternativa al viejo debate izquierda-derecha, pues más allá de posiciones polares se estaría dando paso a una actitud distinta frente a la incertidumbre generada por el proceso de globalización.

La subpolítica no viene a convertirse en una forma sustituta de valoración de la vida pública, antes bien, viene a ser una mirada alternativa para entender y afrontar los retos que genera la incordial sociedad del riesgo. Pero por si misma no es la solución, sino es apenas un acercamiento a la misma. Este underground de entendimiento de la vida política solo sería posible bajo el abandono de los cánones inservibles de la acción social. No es un tema menor si se concibe la idea de revitalizar la vida pública desde un espacio allende las instituciones y las legislaciones locales. Para ello sería indispensable una recreación de la ciudadanía que vaya más allá de los derechos y los deberes establecidos y auspiciados por el liberalismo conservador.

Aunque por su propia confección esta idea parece utópica, lo cierto es que se impone como tema urgente la adopción de una visión que conciba la idea de ciudadanía más allá del paradigma dominante que la delimita al ejercicio lineal de los derechos y obligaciones y la conmina a ser espectadora pasiva del procedimiento democrático. Si algún tipo de beneficio se puede extraer de la sociedad del riesgo es ese propio riesgo que la sociedad debe asumir al ejercer proactivamente su instinto participativo, demandante y contestatario que orille definitivamente a comprender que el ejercicio del poder se decante por otro registro.

\footnotetext{
${ }^{11}$ Idem, p. 33.

${ }^{12}$ Idem, p. 56
} 


\section{NACIONALISMO METODOLÓGICO}

Ulrich Beck fue ante todo un sociólogo político, por eso la importancia que él le da a la sociología estriba en que el estudio de las sociedades deriva necesariamente en la forma en que aquellas están organizadas, y ese marco de relaciones complejas en la historia contemporánea se perfila en lo que genéricamente conocemos como el Estado-Nación: "El Estado hace las veces del creador, del controlador, garante de la sociedad. Las sociedades se conciben como contenedores o continentes que surgen y se afirman en el ámbito del Estado"13.

De acuerdo con Beck, en torno al Estado-nación surge la concepción en los estudiosos de las ciencias sociales y políticas del nacionalismo metodológico, que es entendida como el ámbito de análisis exclusivamente doméstico de las relaciones de poder y autoridad. Todo cabe en el Estado-Nación, sabiéndolo acomodar, desde la cuestión de la defensa de la soberanía a través de la milicia hasta la hechura de la política económica desde los Ministerios de Hacienda. Como dirían los sistémicos, todo se resuelve en un marco lógico autorreferencial. Esta es la noción fordista, taylorista y keynesiana de relación entre el Estado de apellido Nación y la Sociedad de apellido Civil.

Pero, según el teórico teutón, con un contrato social que tuvo auge en la Posguerra de mitad del siglo XX, no se puede comprender un contexto como el que trajo la Posguerra Fría de finales del mismo siglo. Por eso, Beck aboga por la transición a un Cosmopolitismo Metodológico que rompa las barreras del Estado-Nación y se funde en el análisis de la transnacionalización de las relaciones políticas y sociales.

Sin embargo, Beck señala que la salida fácil que encuentran las interpretaciones que abordan la situación actual es calificar a toda relación social y política con el prefijo post. Así se conformó el mundo de los autores, las teorías y las escuelas de pensamiento postmodernos que cuentan con múltiples seguidores pero que adolecen de una contradicción de origen: el prefijo post indica lo que ya no está pasando, pero no lo que está ocurriendo realmente. Beck dice que la palabra post es como un bastón para ciegos que utilizan los intelectuales para evadir el análisis de la realidad ${ }^{14}$.

De hecho, la confección de la realidad que realizan los posmodernos adolece de una falla de origen, pues dan por sentada la muerte de todas las pautas que posibilitaron los procesos de modernización y, aunque muchos de esos procesos están en desuso o fuertemente debilitados, lo cierto es que se siguen sosteniendo como formas no ideales, situación que imposibilita hablar de una transición definitiva hacia nuevos canales de interpretación conceptuales y lexicográficos.

\footnotetext{
${ }^{13}$ Ulrich Beck, Libertad o capitalismo. Conversaciones con Johannes Willms, Barcelona, Paidós, 2002, p.8.

${ }^{14}$ Ulrich Beck, "Políticas alternativas a la sociedad del trabajo" en Ulrich Beck, et. al. Presente y futuro del Estado de Bienestar: el debate europeo, Buenos Aires, Ediciones Miño y Dávila, 2001.pp. 13-15.
} vol.08, no.03, Rio de Janeiro, 2015.pp. 1760-1780 1766 
El caso preclaro es el del Estado que aunque ha perdido su vínculo con la Nación, sigue siendo, en el plano local, el referente donde se dirime el debate público y las relaciones de poder y, en el orden internacional, el actor que, aunque debilitado por otros actores poderosos en la constelación transnacional, es concebido como el depositario final de todas las relaciones sociopolíticas y socioeconómicas que se dan el marco de ese sinuoso camino que conlleva el proceso de globalización contemporáneo.

Por esas razones, para Beck la importancia de transitar del nacionalismo metodológico al cosmopolitismo metodológico radica justamente en afianzar los procedimientos interpretativos que intentan explicar de qué manera los cambios radicales experimentados en las últimas cuatro décadas, sobre todo en el plano económico, dan un perfil cualitativamente distinto al quehacer de los Estados a través de sus administraciones públicas locales.

\section{CATEGORÍAS ZOMBIS}

Las transformaciones profundas en el marco de las relaciones de poder a nivel internacional llevaron a Beck a pensar que las disciplinas sociales tenían la impronta de renovarse o morir. Beck pone de manifiesto que las ciencias sociales hacen uso a granel de categorías zombis, es decir, concepciones y elementos de análisis heredados del pasado de la teoría social y política que actúan como entes medio vivos y medio muertos en el presente. En otras palabras, las ciencias sociales continúan utilizando concepciones que ya no pueden explicar, o al menos ayudar a entender, el derrotero de los asuntos públicos en pleno proceso de globalización. Esto da como resultado que las ciencias sociales sean disciplinas del terror, poco pertinentes, ineficaces y absurdas al tratar de emprender la comprensión del mundo actual ${ }^{15}$.

En palabras de Beck: "Las categorías zombis son categorías vivas-muertas que rondan por nuestras cabezas y pueblan nuestra visión de realidades que no dejan de desaparecer ... En efecto las categorías zombis proceden del horizonte vivencial del siglo XIX, de la anteriormente mencionada primera modernidad, y hacen que nos volvamos ciegos, al proceder de manera analítica-apriorística, a la experiencia y dinámica de la segunda modernidad"16.

SI hiciéramos un ejercicio de revisión categorial y conceptual que pusiera en evidencia la vigencia de nociones como el Estado, la Sociedad, la Democracia, la Legitimidad, el Poder Político, los Partidos Políticos, el Bienestar o la Sociedad nos encontraríamos con que la manera en que estos conceptos fueron pensados en el siglo

\footnotetext{
15 Jonathan Rutherford, "Categorías zombis: Entrevista a Ulrich Beck" en Beck, Ulrich y Elisabeth Beck-Gernsheim, La individualización. El individualismo institucionalizado y sus consecuencias sociales y políticas, Barcelona, Paidós, 2003, pp. 339355 .

${ }^{16}$ Ulrich Beck, Libertad o capitalismo. Conversaciones con Johannes Willms, Barcelona, Paidós, 2002, p.14. vol.08, nº. 03, Rio de Janeiro, 2015.pp. 1760-1780 
XX resulta ya insuficiente para explicar una realidad tan cambiante y porosa como la que se manifiesta en el proceso actual de globalización.

Si esto fuera un problema eminentemente académico no habría por qué preocuparse tanto, empero lo grave del asunto es que las categorías y los conceptos zombis dan como resultado instituciones zombis, esto es instituciones públicas que se han vuelto ineficaces para las tareas que están destinadas a cumplir. En el ámbito académico, la utilización de conceptos zombis da como resultado docencia e investigación zombi, para ya no hablar de quien enseña o hace uso de los mismos ...

El caso más emblemático es la concepción del Estado que se sigue pensando hasta nuestros días a la usanza weberiana (por señalar la línea de interpretación politológica dominante en la materia), cuando en la práctica es un hecho que, en muchas regiones del planeta, se ha dado un adiós definitivo al monopolio de la violencia por parte de las autoridades locales, al presentarse una disputa evidente por dicho monopolio por parte del crimen transnacional, lo cual deviene en un oligopolio de la violencia.

O qué decir del Estado concebido por la tradición marxista como una derivación del capital, cuando en nuestros días el capitalismo no necesita ni de Estado, ni de relaciones de clase, ni de trabajo, para subsistir. Y finalmente cómo explicar el Estado desde su relación con la Nación, cuando se ha visto en la práctica que dicha relación es ya inexistente como lo demuestran los problemas de gobernabilidad en las democracias y de legitimidad en los gobiernos locales.

Por esos motivos, lo que Beck nos propone es hacer una revisión exhaustiva sobre la vigencia del léxico con el que, desde las diversas ciencias de lo social, analizamos la vida pública. Y sobre todo, si llegamos a la conclusión de que el nacionalismo metodológico y sus categorías zombis no es opción, entonces darle santa sepultura y comenzar a configurar un nuevo léxico que reinterprete la viscosa y mutante realidad social desde la mirada de un cosmopolitismo metodológico.

Ello implicaría múltiples cuestiones a revisión, pero quizá la más significativa tendría que ver con ponderar hasta qué punto siguen siendo viables los referentes teóricos más socorridos por el análisis político para la creación de ciencia de lo social. En otras palabras: ¿se puede hablar de ciencia política con conceptos y categorías que no explican ya la realidad social?

\section{GLOBALIZACIÓN}

Un primer acercamiento al tema de la globalización en la obra de Beck se dio a partir del trabajo conjunto que realizó junto con Anthony Giddens y Scott Lash ${ }^{17}$ en torno a la categoría de Modernización

\footnotetext{
${ }^{17}$ Ulrich Beck, et. al., op. cit.
} 
Reflexiva, que sirvió de parteaguas teórico en los años noventa del siglo pasado como entendimiento de la dinámica del mundo de fin de siglo, en eso que tímidamente se comenzaba a llamar proceso de globalización.

En ese alegato, la modernidad no era unidimensional ni epocal, sino que se verificaba en periodos de transformación. En esta secuencia de modernidades, Beck traza una separación definitiva con los autores y las teorías posmodernas, al afirmar que la modernidad no ha desaparecido, sino, antes bien, se ha radicalizado.

En términos de Beck la primera modernidad es la noción de una sociedad que se constituye en el marco de un Estado -Nación, caracterizada por el pleno empleo y por una política del Estado de Bienestar; constituida entonces por una plena ocupación; con identidades colectivas preexistentes relativamente homogéneas y definidas por el mito del progreso con la seguridad de que cualquier problema generado por el desarrollo industrial puede ser superado por los avances endógenos. Sin embargo, Beck cree que este modelo, cuyo auge se dio en la posguerra de 1945, es puesto en tela de juicio por una radicalización de la modernización llamada globalización.

Por ello, define la segunda modernidad como el proceso donde la individualización de la sociedad alcanza su máxima expresión, dando al traste con la visión asistencialista y desarrollista de la primera modernidad. Según Beck, existe un individualismo institucionalizado, ya que las instituciones esenciales, como los derechos sociales y los derechos políticos se orientan hacia el individuo y no hacia los grupos, amén de que ambos están acompañados de desafíos fundamentales de la sociedad moderna como son la merma del trabajo asalariado y las crisis ecológicas, que ponen en entredicho el modelo de racionalidad del industrialismo fordista-tayloristakeynesiano.

Por ese motivo, para Beck la globalización significa el fin de una concepción concreta de la política que se constituyó desde tiempos de la Paz de Westfalia en 1648, pasando por el liberalismo decimonónico, y que tuvo su esplendor en la posguerra de 1945. Este es el fin de una política organizada territorialmente, dentro del marco soberano de los Estados-Nación.

Por ello, para el sociólogo alemán, la necesidad de contar con un nuevo sello explicativo es fundamental para las ciencias sociales. Empero, los enfoques que se han dado siguen gravitando la esfera estrictamente local, en un contexto en el cual la lógica diría que se debe contar con soluciones globales a problemas globales, de la misma forma que operó el esquema de antaño que pugnaba por las soluciones locales a los problemas locales. La tragedia de nuestros días es que se impone la ilógica de las soluciones locales a los problemas globales, dando como resultado un desencantamiento con la política y lo político, con el consecuente agravante y menosprecio por las instituciones del Estado y su correlato en la administración pública.

De ahí que el vilipendio de la actividad estatal esté en el epicentro del debate público y que los discursos antipolíticos estén a la orden del día, lo cual entroniza a otro tipo de actores que aprovechando la debilidad de las 
instituciones para remediar los asuntos perentorios de la sociedad, propugnan por un nuevo orden con apego a la tradición ultra conservadora del liberalismo: el Estado en su mínima expresión, reducido a funciones de gendarmería. Esto es el paso del Estado Social al Estado Penal como apunta Danilo Zolo.

Esta nueva realidad es la que, siguiendo a Beck, hace tan complejo el análisis del proceso de globalización. Y a diferencia de otros autores o posiciones ideológicas que asemejan la globalización con referentes estrictamente económicos (el mercado, los flujos de capital, las inversiones), el sociólogo alemán advierte que ésta debe ser tratada con arreglo a valores políticos, puesto que en la medida que las relaciones económicas emanadas del mercado perturban el derrotero de lo público estatal y todas las demás relaciones sociales, se establece que entonces la globalización es un concepto político.

Esta es una manera audaz de interpretar el proceso de globalización, ya que, en términos generales, casi todas las definiciones y explicaciones que analizan dicho proceso ponen el énfasis en la economía mundial (la regionalización, los tratados de libre comercio) dejando fuera, o menospreciando, como en el caso de Kenichi Ohmae, todos los demás referentes de la vida pública.

Por ese motivo, al convertirse en tema de interés político, la globalización adquiere un novedoso cariz que la sitúa en un derrotero de análisis poco inspeccionado pero necesario de plantear en momentos donde el menosprecio por lo político pareciera ser la lógica de todo discurso panegírico sobre este proceso. En ese sentido, para Beck, si bien existe una radicalización de la modernidad que dio como resultado el proceso de globalización que hoy conocemos, también es menester radicalizar la visión de la política y lo político para que siga siendo vigente, como se analizó líneas arriba al hablar de la subpolítica.

Con ese marco referencial, Beck apuesta por la confección de tres conceptos que articulen el análisis del proceso de radicalización de la vida pública: globalidad, globalismo y globalización.

La globalidad se entiende como aquel proceso histórico, tanto antiguo como contemporáneo, que permite la comunicación e intercambio de mercancías entre civilizaciones e imperios. El concepto defiende, según Beck, la idea de que desde hace bastante tiempo vivimos en una sociedad mundial, permitiendo tener interacciones, una de ellas, la más relevante, por medio del comercio marítimo que las grandes potencias realizaban desde el siglo XV.

La globalidad, en palabras de Beck, afirma que "vivimos en una sociedad mundial, de manera que la tesis de los espacios cerrados es ficticia" ${ }^{18}$, por lo tanto no es sostenible la idea de que la globalización, entendida como un fenómeno nuevo, trajo al escenario la interacción mundial, pues esta característica ya existía con antelación.

Lo que si se plantea diferente es la noción de lo que Beck acuña con el término globalismo, mismo que será planteado como la ideología que pugna por el libre mercado a partir de la visión neoliberal, donde el mercado

${ }^{18}$ Ulrich Beck, ¿Qué es la globalización? Falacias del globalismo, respuestas a la globalización, Barcelona, Paidós, 1998, p. 28. vol.08, nº. 03, Rio de Janeiro, 2015. pp. 1760-1780 
asume funciones por encima de los gobiernos locales y en pleno avasallamiento de los procedimientos democráticos. El quid del asunto tendría que ver con la nula legitimidad de los actores transnacionales que haciendo uso de la noción de la libre competencia económica, dilapidan toda esencia democrática. De esta manera, el globalismo vendría a ser el discurso político que justifica el modelo económico neoliberal y que intenta fundir como uno solo el proceso globalizador con la ideología del modelo económico liberal radical.

Por último, la globalización se entenderá como un proceso multidisciplinario donde la difusión y el acceso a las telecomunicaciones, los avances científicos y tecnológicos, los medios de comunicación masiva y las nuevas herramientas de la investigación científica, han potencializado los procesos de conocimiento con una vertiginosidad nunca antes vista en la historia de la humanidad.

\section{INDIVIDUALIZACIÓN}

De acuerdo con Beck, el fenómeno del individualismo se asocia íntimamente con la segunda modernidad, pero sobre todo en su vertiente de individualismo institucionalizado, el cual no solo se trata de una forma de percepción del individuo (la individualidad), sino del fenómeno que eclipsa a las instituciones esenciales del Estado al verse mermadas en su capacidad de respuesta a los problemas perentorios de la sociedad.

Esta lógica orilla a los individuos a desarrollar respuestas biográficas, mismas que hacen que cada cual se haga cargo de sus propios asuntos y necesidades (la educación, la salud, el trabajo), situación que da al traste con los postulados colectivos que promovió la modernidad de la primera mitad del siglo XX: la solidaridad, la cohesión y la cooperación.

Individualización no significará lo mismo que individualismo pues éste último se encuentra coligado a la sociedad del ego y por la psicología para explicar la autonomía individual. La individualización es, en cambio, un proceso que transforma institucionalmente las actitudes políticas de la sociedad.

Siguiendo a Beck: "La individualización es individualismo institucionalizado. Vale decir que las instituciones esenciales, como los derechos sociales y los derechos políticos se orientan hacia el individuo y no hacia los grupos"19.

La individualización tiene que ver con el cambio de referentes que los individuos experimentan a partir de las transformaciones en el ámbito económico y que afectan su vida en términos sociales. Así, mientras la política económica de libre mercado abre las fronteras territoriales y se profundiza el comercio y la especulación, en paralelo se manifiesta una economía política de la inseguridad expresada en el resquebrajamiento de las bases del Estado social.

${ }^{19}$ Ulrich Beck, "Políticas alternativas a la sociedad del trabajo" en Ulrich Beck, et. al. Presente y futuro del Estado de Bienestar: el debate europeo, Buenos Aires, Ediciones Miño y Dávila, 2001, p. 14. 
Esta nueva situación se traduce en la fragilización de las trayectorias de los individuos, expresada por ejemplo en la pérdida de sus seguridades: al empleo, al salario, al patrimonio, al bienestar en la senectud. Es una suerte de programación de la pobreza a futuro, en la cual la demanda de mayor flexibilización laboral se asume como la nueva ley empresarial solapada por el Estado. ${ }^{20}$

Este proceso ha supuesto la alteración de las condiciones de vida del individuo, pues se le traspasan de facto los riesgos que produce el desvanecimiento del Estado social y la entrada en escena de la empresa privada. El individuo queda conferido a una suerte de desamparo institucional en la medida que las políticas gubernamentales se desentienden de él.

Yo utilizo el concepto de individualización para explorar no sólo la manera como la gente hace frente a estas transformaciones en términos de identidad y conciencia, sino también cómo han cambiado sus situaciones existenciales y sus modelos biográficos. La individualización libera a la gente de los roles tradicionales pero también la condiciona de muchas maneras. En primer lugar, los individuos se alejan de las clases basadas en el estatus. Las clases sociales se han destradicionalizado. Esto lo podemos ver en los cambios producidos en las estructuras familiares, en las condiciones de la vivienda, en las actividades, en el ocio, en la distribución geográfica de las poblaciones, en la afiliación a sindicatos y la suscripción a clubes, en la manera de votar, etcétera. En segundo lugar, las mujeres se han desvinculado de su "destino de estatus", que las obligaba a quedarse a trabajar en el hogar y a recibir su sustento de un marido. La sociedad industrial se ha basado en las posiciones desiguales entre hombres y mujeres, pero la modernidad no vacila ante la puerta de la vida familiar. Toda la estructura de los vínculos familiares se encuentra bajo la presión de la individualización, y está emergiendo de una nueva familia negociada, provisional, compuesta de múltiples relaciones: la "posfamilia". En tercer lugar, las viejas formas de la rutina y disciplina laborales se están viviendo abajo con la emergencia de los horarios laborales flexibles, el subempleo pluralizado y la descentralización de los lugares de trabajo. ${ }^{21}$

Este modus vivendi de talante líquido ha planteado a los individuos nuevos desafíos en términos de creación de identidades y replanteamiento de sus formas de vida. Ello se explica por al abandono que han sufrido por parte de las instituciones del Estado, mismas que les brindaban ciertas seguridades. La paradoja es que si antes esos individuos, agrupados en sociedad, se definían en oposición a las medidas gubernamentales, en el actual escenario global donde las acciones estatales tienden a disminuir, se configura una nueva sociedad que ya no repudia o cuestiona sino añora esas medidas.

\footnotetext{
${ }^{20}$ Se estima que alrededor de mil millones de personas están desempleadas o subempleadas (con trabajos flexibles) en todo el mundo, lo cual nos habla del paso de la sociedad del pleno empleo a la sociedad del pleno desempleo. Jeremy Rifkin, "Tiempo libre para disfrutarlo o hacer filas de desempleados" en Luis Álvarez (Coordinador), Un mundo sin trabajo, México, Dríada, 2004, p. 17.

${ }^{21}$ Ulrich Beck y Elisabeth Beck-Gernsheim, La individualización. El individualismo institucionalizado y sus consecuencias sociales y políticas, Barcelona, Paidós, 2003, pp. 339-340.
} 
En síntesis la individualización cambia de diversas maneras las condiciones de vida de la gente, su orientación, su necesidad de justificarse y de tomar decisiones. Así concebido, este proceso de la globalización resulta ser una disolución radical de la tradición, una liberación del individuo, misma que representa el debilitamiento de la familia, antaño garantizada y regida por la tradición, y del propio orden social y económico religiosamente establecido por la providencia del Estado.

De ahí que la individualización signifique la emergencia de una dinámica institucional que tiene como destinatario al individuo y no al colectivo y cuyo efecto más dramático se expresa en la precariedad y flexibilidad laboral.

\section{FLEXIBILIDAD LABORAL}

El concepto de trabajo ha experimentado un cambio de valor radical. Es difícil hacerse una idea aproximada al respecto. En los comienzos de la civilización occidental, así como en su etapa moderna-ilustrad el trabajo se convierte en la característica primordial de la identidad social, así como de la posición social y de la seguridad existencial de las personas.

El trabajo era visto como la consecuencia de la racionalización de la sociedad. Esta visión cobró especial auge en el contexto de la posguerra del siglo XX, cuyo correlato en la dinámica económica posicionó la tesis del pleno empleo como el motor a partir del cual se organizó la vida pública. El individuo existía y tenía identidad en el trabajo y en el salario. El modelo fordista-taylorista-keynesiano permeó la dinámica social de prácticamente tres cuartos del siglo pasado.

El trabajo daba seguridad a largo plazo, podría decirse hacía menos tensa en el individuo/obrero la idea del futuro, pues al presentarse como empleo para toda la vida y con los consecuentes derechos sociales inherentes a él (la contratación colectiva, el seguro de desempleo, el acceso a las seguridades sociales), se ponía en marcha un modelo económico que aseguraba cierta estabilidad política. Esa fue la premisa sobre la que se asentó el llamado Estado Social de Derecho o de Bienestar.

De acuerdo con Beck el trabajo asalariado era una precondición para que la idea de la democracia representativa estuviera viva. Ese modelo aseguraba la emergencia de un ciudadano-trabajador que aseguraba su autoconciencia y su existencia financiera mediante la participación en el mercado laboral, y que en su tiempo libre se involucrara, así fuera solo testimonialmente, mediante el sufragio, en la deliberación democrática.

El trabajo se constituyó en principio y fundamento de la sociedad burguesa, por ello la fábrica fue el epicentro de la primera modernidad, el lugar en el que se forjó el destino de clase como experiencia social, la idea de la vida mejor para las generaciones futuras (los hijos de los trabajadores). 
Empero, la segunda modernidad eclipsa este contrato social de la posguerra y da pauta a una nueva lógica económica asentada en un modelo de empleo flexible. Se impone la idea de que el trabajo ya no es para siempre, que la contratación laboral es individual y por tiempo determinado y se suprimen los derechos del bienestar: el seguro de desempleo, las prestaciones económicas, y la seguridad en la vejez (la jubilación). Siguiendo a Beck:

Cuando el capitalismo global de los países más desarrollados destruye el nervio vital de la sociedad del trabajo, se resquebraja también la alianza histórica entre capitalismo, Estado asistencial y democracia ... en el sentido de que la democracia se apoya en el reparto del trabajo remunerado-. El ciudadano tenía que ganar su dinero de una u otra manera para dar sentido a su derecho de libertad política. El trabajo remunerado sostiene y fundamenta constantemente no sólo la existencia privada, sino también la propia política ${ }^{22}$.

En este nuevo acuerdo de la Posguerra Fría (conocido también como Consenso de Washington), el papel que juega el descentramiento del Estado es fundamental. El achicamiento y supresión de tareas que antaño le dieron razón de ser al Estado se pulverizan o bien se minimizan. A este proceso se aparejaron los avances tecnológicos, telecomunicativos y científicos que hicieron prescindible mucha mano de obra, o bien la orillaron a una situación de extrema flexibilidad ${ }^{23}$. Explica Beck:

En el lugar de la figura social del empleado y del trabajador como contrapuestos a capitalistas y empresarios aparece, por una parte, el modelo del trabajador autónomo y, por otra, la del empresario público. El trabajador autónomo sabe que ya no le es posible por más tiempo continuar contando con un trabajo que otros estén obligados a darle; si no lo tiene en cuenta será él el culpable y no los otros. Sabe, y procede en consecuencia, que <su> trabajo ha de basarlo y hallarlo en el sentido de un valor de uso ampliado (y ahí están implicados los tres factores, el social, la utilidad y el valor). Esto presupone no sólo una gran identificación con las necesidades ajenas, sino también con el trabajo. El trabajador autónomo siempre conlleva, en este sentido, trabajo en sí mismo y para los demás ${ }^{24}$.

En ese sentido, el apotegma del pleno empleo pareciera reconfigurarse en la máxima del pleno desempleo como lógica y dinámica imperante en el proceso globalista de la globalización. La flexibilidad laboral se convierte así en uno de los fenómenos más dramáticos de nuestros días y con consecuencias que ponen en riesgo incluso el propio futuro de la democracia.

\section{COSMOPOLITISMO}

Se pudiera decir que aunque el abordaje de la idea de cosmopolitismo está planteada desde la obra primigenia de Beck, lo cierto es que es en sus últimas obras donde detalla y discute con mayor ahínco esta tesis, por lo que no es casual que dedique prácticamente libros completos a dilucidar y explicitar esta concepción. Para

\footnotetext{
${ }^{22}$ Ulrich Beck, ¿Qué es la globalización? ... p. 97.

${ }^{23}$ Ulrich Beck, Un nuevo mundo feliz. La precariedad del trabajo en la era de la globalización, Barcelona, Paidós, 2000.

${ }^{24}$ Ulrich Beck, ¿Qué es la globalización? ... p.206.
} 
Beck la utilidad del término debe verse con referencia a la manera en que la política puede ser repensada, en un escenario caracterizado por la incertidumbre que genera la globalización y la poca capacidad de respuesta que ofrecen los Estados para darle cauce a las demandas básicas del bienestar social.

La idea que subyace en la noción cosmopolita es la reconfiguración de la política a través de la política. Ante el desgaste, la descentralidad y la mutilación de la actividad política conviene estudiarla a partir de sus orígenes, de para qué fue creada, cuáles eran sus propósitos, por qué la necesidad de su diseño y de qué manera puede insertarse en el proceso de globalización y, más específicamente, cómo puede hacerle frente a la ideología imperante en la globalización: el globalismo.

Por eso la idea de revisar la tesis cosmopolita tiene que ver, sobre todo, con retomar la visión de la política pero desde un enfoque global, donde la interrelación económica, sociopolítica y cultural entre Estados, empresas, organizaciones, asociaciones, grupos e individuos ha llegado para quedarse.

Beck publicó una trilogía de libros que abordan la forma en que la mirada cosmopolita debe ser atendida por las ciencias sociales a efecto de que se comprendan mejor los nuevos derroteros que impone el mundo globalizado. Es así que tanto en Poder y contrapoder en la era global. La nueva economía política mundial, como en La mirada cosmopolita o la guerra es la paz y en La Europa cosmopolita. Sociedad y política en la segunda modernidad, el sociólogo alemán pone el acento en el nuevo diseño reflexivo de las principales categorías sociales.

En Poder y contrapoder en la era global. La nueva economía política mundial, Beck analiza el actual contexto político mundial y reflexiona acerca de cuáles serían las premisas básicas para plantear la nueva discusión sobre el quehacer político dado un rumbo económico marcado por la incertidumbre. Para ello retoma su premisa de la transición de la primera a la segunda modernidad -desarrollada en sus anteriores escritos- donde muchos referentes del Estado-Nación se fueron desdibujando provocando que su soberanía y legitimidad quedaran en entredicho, sobre todo porque el mercado se apropió de muchos espacios que antes eran exclusivos del ámbito gubernamental. Ante este nuevo rumbo Beck observa una nueva configuración de las relaciones de poder, donde los Estados han sido desplazados como los actores predominantes para la toma de decisiones en los ámbitos local y mundial.

El metajuego que cambia las reglas de la política mundial significa una segunda Great Transformation. Los Estados ya no constituyen la única arena de la actuación colectiva en el sentido de marcar el espacio y las reglas del juego de la actuación política (incluidas las de las irrenunciables instituciones sociales donde se toman y ejecutan las decisiones colectivas). Con el metajuego reflexivo, irrumpe en la realidad la pregunta de hasta qué punto los fundamentos mismos del poder estatal se convierten en objeto de estrategias de poder políticas y económicas a nivel mundial. Pero esto significa que es la globalización y no el Estado quien define y transforma las arenas de la actuación colectiva. 25

\footnotetext{
${ }^{25}$ Ulrich Beck, Poder y contrapoder en la era global. La nueva economía política mundial, Barcelona, Paidós, 2004. p.26. vol.08, nº. 03, Rio de Janeiro, 2015.pp. 1760-1780
} 
De esta forma, el cosmopolitismo que se pregona es aquel que desecha la visión política tradicional del Estado-Nación como el eje central de las decisiones al considerarla obsoleta. Sin embargo, al mismo tiempo, descarta la óptica de la concepción globalista de la globalización, según la cual el relevo de la actividad política por el reino del libre mercado ha llegado para quedarse.

Asimismo, para la mirada cosmopolita las polaridades interior/exterior, nacional/internacional, yo/el otro son falsas dicotomías, pues ya no se puede entender la realidad si no se analizan las nuevas mezclas de términos, antaño antípodas, que se están perfilando con vertiginosidad. En la concepción cosmopolita, la existencia de Estados, asociaciones e individuos debería derivar en un espacio de nuevas experiencias que se vinculen con la globalización pero no de manera forzada, sino por encima de la ideología imperante y en función de intereses recíprocos.

Hay que advertir que esta manera de entender la política estaría pensada en términos de reconocer las diferencias contextuales (socioculturales) no para reestablecer atisbos nacionales o pregonar neonacionalismos, sino para identificar posibles vías de cooperación, auxilio y alianzas primordialmente entre gobiernos, autoridades locales, grupos sociales e individuos para hacer frente a los desafíos de la globalización y a las exigencias del globalismo.

De acuerdo con esta visión, si se sigue optando por las salidas nacionales para resolver problemas mundiales se echaría el esfuerzo en saco roto, puesto que los retos globales son también de tendencia cosmopolita. Por ello, surge la necesidad de afrontar los problemas cosmopolitas con instrumentos del mismo talante. Si los desafíos globales afectan por igual a todos, cada actor está obligado, aún a pesar de las dificultades que eso conlleva, a pensar en sus pares para, juntos, afrontar esos dilemas. Surgiría así la obligación del razonamiento político cosmopolita.

Si se piensa en algunos bemoles de corte mundial que requieren el concurso de la reflexión cosmopolita, tendríamos por ejemplo los relativos al paro masivo, la creciente migración, las crisis financieras mundiales, el enorme poderío e influencia de las organizaciones financieras internacionales y las empresas transnacionales, la delincuencia organizada internacional, las catástrofes ecológicas y los problemas referentes a la salud pública.

El cosmopolitismo que pregona Beck no está concebido desde una tradición teórico-filosófica, sino que deviene de la realidad que imponen los procesos de cambio generados por la globalización. El terreno donde hunde sus raíces es aquel que mira la necesidad de reconocer la complejidad del mundo de nuestros días caracterizado por la incertidumbre económica, política, sociocultural y medioambiental.

Por ello, el cosmopolitismo a la vez de estar planteado como instrumento para interpretar la nueva realidad social, tiene también un carácter suspicaz. En su texto La mirada cosmopolita o la guerra es la paz, Beck plantea que algunas categorías que explicaron el mundo de la posguerra están siendo diluidas por la globalización. 
La lucha de clases, la relación capital-trabajo, las relaciones sociales, la familia monógama y la bipolaridad ideológica han perdido su eficacia esclarecedora para definir el mundo del siglo XXI.

Hoy ya no se discute si el patriotismo es demasiado pequeño pero practicable, y el cosmopolitismo, en cambio, magnánimo pero frío y difícil de practicar. Hoy se habla de que la realidad misma se ha vuelto cosmopolita (...) el cosmopolitismo ha dejado de ser una simple idea de la razón, aún muy disputada, para emigrar -no entramos en las numerosas distorsiones sufridas en el proceso- de los sueños filosóficos a la pura y simple realidad. Más aún, se ha convertido en el sello de una nueva era, la era de la modernidad reflexiva, en la que se difuminan las fronteras y diferenciaciones del Estado nacional, para ser nuevamente tratadas como política de la política. Para este mundo que se ha vuelto cosmopolita necesitamos urgentemente una nueva manera de mirar, la mirada cosmopolita, si queremos comprender la realidad social y política en que vivimos y actuamos. Así pues, la mirada cosmopolita es resultado y condición de la reestructuración conceptual de la percepción. ${ }^{26}$

Según Beck hace falta una nueva trayectoria de análisis político y social que se enfoque desde la óptica cosmopolita a efecto de abordar los problemas globales desde la multiperspectiva y no cerrar el candado con la monoperspectiva del nacionalismo metodológico. Aunque la reflexión cosmopolita pueda no llegar a ser convincente, habría que estar de acuerdo con Beck cuando afirma que los otros intentos por explicar el actual derrotero global no son satisfactorios, dado que las contradicciones e incoherencias permean las tesis que abogan por el fin de la historia y el fin de la política, o bien se refugian en el posmodernismo para explicar lo que ya no está pasando, pero no lo que está aconteciendo o, peor aún, seguir haciendo acopio de la mirada nacional para explicar una realidad que ha superado esa visión metodológica.

Se puede considerar que la visión cosmopolita supera las redes teórico metodológicas de la perspectiva nacional en tres aspectos: en principio, propugna por nuevas reglas en el contexto político mundial dando prioridad a la vertiente transnacional para abordar los conflictos de poder (conglomeración de Estados para darle funcionalidad a las relaciones de poder, por ejemplo para limitar el poder de los mercados). En segundo lugar, propone el abandono del concepto tradicional de Estado, pues las decisiones que se toman al interior de aquél ahora incluyen a actores globales que están fuera del espacio de legitimidad del ámbito estatal, como las organizaciones financieras internacionales y las empresas transnacionales.

Un tercer aspecto es el abordaje de la política a partir de la política, el asumir que la actividad política es propia de, valga la expresión, actores políticos que, en ese sentido, demandan un radio de acción que los ponga en ventaja en la conformación de las estructuras reales de poder. De ahí la importancia de modificar la óptica tradicional del poder estatal por el de poder estatal cosmopolita transnacional.

${ }^{26}$ Ulrich Beck, La mirada cosmopolita o la guerra es la paz, Barcelona, Paidós, 2005, p. 10. vol.08, nº. 03, Rio de Janeiro, 2015.pp. 1760-1780 
Como parte de su trilogía sobre el cosmopolitismo, Beck analiza en el último de estos libros (La Europa cosmopolita. Sociedad y política en la segunda modernidad) como se podría materializar su planteamiento partiendo de la experiencia histórica de la Unión Europea.

Aunque a lo largo de sus obras anteriores el autor propone referencias específicas al camino cosmopolita que debe seguir Europa, es en este texto donde desarrolla con mayor claridad y profundidad la aplicación de la metodología de la mirada cosmopolita. Beck se propone analizar los vericuetos que la historia de la integración de Europa ha sufrido en los años recientes y particularmente la vía cosmopolita como la utopía más eficaz que pudiera acordar ese conglomerado de países.

¿Adónde nos lleva la europeización, y qué resultados ha tenido en este momento? Ni la euforia ni el escepticismo en relación con una nueva Europa ampliada pueden hacernos olvidar que Europa todavía no ha sido verdaderamente comprendida, entendida, Esta forma históricamente única y singular de crear una comunidad de sociedades y Estados distintos se sustrae a todas las categorías y conceptos al uso. El ejemplo de Europa muestra con especial claridad hasta qué punto nuestros conceptos políticos y el instrumental teórico de las ciencias sociales se han vuelto inapropiados y ajenos a la realidad, hasta qué punto siguen encerrados en el marco teórico del nacionalismo metodológico. ${ }^{27}$

Esto es cierto en la medida que aunque actualmente se hable mucho de la Unión Europea, su modelo político tiene que ser repensado, principalmente porque no ha respondido a las expectativas de integración económica, política y social, y más aún, porque no ha encontrado la fuerza capaz que le permita presentarse al mundo como una alternativa real de poder a la hegemonía estadounidense y al proyecto neoliberal. Empero, aún con lo imperfecto de esta experiencia histórica, de esta forma regional de organización, se han creado conflictos para entenderla desde el léxico tradicional de la política.

Según esta lógica, a pesar de que la teoría hable de unidad europea en la práctica ese hecho está lejos de ser una realidad, porque la mayoría de los Estados miembros siguen pensándose en términos nacionales, lo cual dificulta la integración y la asimilación de Europa como un Estado transnacional. En ese tenor, se sigue privilegiando la semántica del o esto o lo otro (propia del modelo nacional para diferenciar a los Estados) y no la máxima del tanto lo uno como lo otro (que sería más acorde al modelo transnacional de corte cosmopolita).

Siguiendo a Beck, la opción por el cosmopolitismo al interior de la Unión Europea tiene que ver con abandonar la mirada nacional y adentrarse al mundo de la transnacionalización, como la vía más adecuada para que el conjunto de Estados actúe como uno solo y haga frente a los retos que impone la forma en que está siendo conducida la globalización.

Esta tesis fue muy criticada por su carácter irrealizable, empero Beck creía que en la medida que no solo se conjuntaran esfuerzos, sino se identificaran intereses, el derrotero del actual proceso de globalización podría

${ }^{27}$ Ulrich Beck y Edgar Grande, La Europa cosmopolita. Sociedad y política en la segunda modernidad, Barcelona, Paidós, 2006. p.15. 
modificarse e incidir de manera positiva en la resolución de los problemas perentorios que hoy aquejan lo mismo a Estados, sociedades, comunidades e individuos.

\section{EPÍLOGO}

La obra de Ulrich Beck fue diferente, se pude decir novedosa. No respondió a exigencias ideológicas ni estuvo planteada como la gran teoría que explicara los pormenores del proceso de globalización. Antes bien, se planteó como una vía de abordaje que intentó analizar el entretelón de las transformaciones cualitativas que trajo consigo la Posguerra Fría. El punto de partida fue la noción de la sociedad del riesgo - presente en la totalidad de la obra del sociólogo alemán-, misma que concatenó con una reflexión política sobre el actual proceso de globalización y sus temas colaterales: el trabajo flexible y el individualismo institucionalizado. Ello le permitió comprender, en el plano teórico, la necesidad de revitalización de las ciencias sociales para que prescindieran del uso y abuso de categorías zombis. En el eje de la vida práctica Beck deseó que su idea sobre el cosmopolitismo no fuera vista como una teoría que se quedara en el baúl académico, sino que fuera enarbolada en el campo de la acción política, pues consideró que solo las respuestas globales que concitaran el esfuerzo de los actores excluidos por el globalismo, podrín hacer frente a los problemas estructurales transnacionales que hoy aquejan la vida de millones de personas a lo largo del planeta.

\section{NOTES ON THE THEORETICAL REFLECTIONS OF ULRICH BECK}

\section{Abstract}

This article provided an overview of the main issues addressed by Ulrich Beck throughout his work, highlighting how his notion of the World Risk Society is the linchpin of the side issues developed in his theoretical reflections ago.

Keywords: Reflexive Modernization, World Risk Society, Subpolitics, Methodological Nationalism, Zombies Categories, Globalization, Individualization, Flexibility Labor and Cosmopolitism

\section{REFERENCIAS BIBLIOGRÁFICAS}

BECK, Ulrich, La mirada cosmopolita o la guerra es la paz, Barcelona, Paidós, 2005. La sociedad del riesgo. Hacia una nueva modernidad, Barcelona, Paidós, 1998. La sociedad del riesgo. Amor, violencia, guerra, Madrid, Siglo XXI de España Editores, 2006. La sociedad del riesgo mundial. En busca de la seguridad perdida, Barcelona, Paidós, 2008. Libertad o capitalismo. Conversaciones con Johannes Willms, Barcelona, Paidós, 2002, 
Poder y contrapoder en la era global. La nueva economía política mundial, Barcelona, Paidós, 2004.

¿Qué es la globalización? Falacias del globalismo, respuestas a la globalización, Barcelona, Paidós, 1998. Un nuevo mundo feliz. La precariedad del trabajo en la era de la globalización, Barcelona, Paidós, 2000.

BECK, Ulrich y Edgar Grande, La Europa cosmopolita. Sociedad y política en la segunda modernidad, Barcelona, Paidós, 2006.

BECK, Ulrich y Elisabeth Beck-Gernsheim, La individualización. El individualismo institucionalizado y sus consecuencias sociales y políticas, Barcelona, Paidós, 2003.

BECK, Ulrich; Giddens, Anthony; Lash, Scott, Modernización reflexiva. Política, tradición y estética en el orden social moderno, Madrid, Alianza Editorial, 1997.

BECK, Ulrich et. al. Presente y futuro del Estado de Bienestar: el debate europeo, Buenos Aires, Ediciones Miño y Dávila, 2001.

\section{Referencias Cibergráficas}

BECK, Ulrich, Un voto a favor del regreso de la historia social. Disponible en URL: http://ssociologos.com/2015/02/03/el-ultimo-ensayo-de-ulrich-beck-elogiando-bauman-un-voto-favor-delregreso-de-la-historia-social/

Trabalho enviado em 01 de setembro de 2015.

Aceito em 01 de outubro de 2015. 